\title{
IDENTIFIKASI KENAMPAKAN ALAM KABUPATEN PACITAN SEBAGAI BAHAN AJAR IPS KELAS V SD
}

\author{
Endah Nurjanah, Muhamad Rifai \\ 1) Prodi Pendidikan Guru Sekolah Dasar Universitas PGRI Madiun \\ 2) Program Magister PIPS Universitas PGRI Madiun \\ Email: ${ }^{1)}$ endahnocta@gmail.com, ${ }^{2)}$ muhamad rifai@yahoo.co.id
}

\begin{abstract}
Abstrak
Penelitian ini bertujuan untuk menganalisis dan mendeskripsikan kenampakan alam Kabupaten Pacitan yang memiliki potensial sebagai bahan ajar IPS kelas V SD. Penelitian ini menggunakan pendekatan kualitatif dengan jenis deskriptif. Sumber data yang digunakan dalam penelitian ini adalah sumber data primer dan sumber data sekunder, sedangkan teknik pengumpulan datanya adalah dengan wawancara, observasi, dan dokumentasi atau arsip. Validasi yang digunakan untuk menguji kebenaran adalah triangulasi sumber penelitian. Analisis data menggunakan model interaktif Miles dan Huberman. Dari penelitian yang telah dilakukan menunjukkan bahwa kenampakan alam Kabupaten Pacitan yang memiliki potensi untuk dijadikan bahan ajar sesuai dengan materi pembelajaran IPS kelas V SD materi kenampakan alam dan buatan, yaitu: (1) Kenampakan alam Pantai Kasap (2) Kenampakan alam Pantai Klayar (3) Kenampakan alam Pantai Pidakan (4) Kenampakan alam Gua Gong (5) Kenampakan alam Gua Tabuhan (6) Kenampakan alam Sungai Maron (7) Kenampakan alam Sungai Cokel (8) Kenampakan alam Sungai Grindulu (9) Kenampakan alam Gunung Limo (10) Kenampakan alam Telaga Sono (11) Kenampakan alam sumber air panas Tirto Husodo.
\end{abstract}

Kata kunci : bahan ajar, IPS SD, kenampakan alam.

\section{Identifying Natural Scenery Portrayal of Pacitan Regency as Learning Sources on IPS Subject for the Fifth Grade Students of Elementary School}

\begin{abstract}
The study aims to analyze and describe Natural Scenery portrayal of Pacitan Regency which is potentially used as Learning Sources on IPS Subject for the Fifth Grade Students of Elementary School. It used descriptive qualitative research design. Source of data used here was primary and secondary data, while the data were collected through interviews, observation, and documentation or collecting archives. The data were validated by testing the truth through source of research triangulation. The data, then, were analyzed by using interactive model of Miles and Huberman. Based on the findings, they showthat natural scenery portrayal of Pacitan Regency can be potentially used as learning sources appropriate for IPS learning materials of natural and non-natural scenery themes for the fifth grade students of elementary school, as follows: (1) natural scenery portrayal of Kasap beach, (2) natural scenery portrayal of Klayar beach, (3) natural scenery portrayal of Pidakan beach,(4) natural scenery portrayal of Gong Cave, (5) natural scenery portrayal of Tabuhan Cave, (6) natural scenery portrayal of Maron river, (7) natural scenery portrayal of Cokel river, (8) natural scenery portrayal of Grindulu river, (9) natural scenery portrayal of mount Limo, (10) natural scenery portrayal of lake Sono, (11) natural scenery portrayal of Tirto Husodo hot spring.
\end{abstract}

Keywords: learning sources, IPS subject of elementary school, natural scenery portrayal 
Avaliable online at http://e-journal.unipma.ac.id/index.php/gulawentah

\section{Pendahuluan}

Ilmu Pengetahuan Sosial merupakan salah satu mata pelajaran yang diajarkan di SD. IPS merupakan bagian dari kurikulum sekolah yang berhubungan dengan peran manusia dalam masyarakat yang terdiri atas berbagai subjek sejarah, ekonomi, geografi, sosiologi, antropologi, dan psikologi sosial. Meskipun saat ini mata pelajaran Ilmu Pengetahuan Sosial penyampaiannya diintegrasikan dengan mata pelajaran lain dalam suatu tema, namun tidak menghilangkan muatan materi yang harus dipelajari siswa dalam mata pelajaran IPS. Tujuan dari pengintegrasian mata pelajaran ini adalah agar pembelajaran menjadi lebih bermakna bagi siswa, sehingga penyusunan materi atau bahan ajar disesuaikan dengan lingkungan, karakteristik, dan kebutuhan peserta didik.

Pada kurikulum yang berlaku saat ini, bahan ajar yang digunakan masih bersifat nasional sehingga beberapa materi kurang sesuai dengan kondisi lingkungan belajar siswa. Umumnya bahan ajar yang digunakan dalam pembelajaran di SD menggunakan kurikulum 2013 edisi revisi 2016 adalah buku guru dan buku siswa. Dalam buku guru maupun buku siswa kelas V SD tema 1.Organ Gerak Hewan dan Manusia, Materi Kenampakan alam dan buatan, pada Kompetensi Dasar 3.1 Mengidentifikasi karakteristik geografis Indonesia sebagai negara kepulauan/ maritim dan agraris serta pengaruhnya terhadap kehidupan ekonomi, sosial, budaya, komunikasi serta transportasi, hanya menampilkan kenampakan alam secara umum atau kenampakan alam secara nasional, dengan pembahasan kenampakan alam secara umum tersebut siswa kurang dalam mengenal dan memahami kenampakan alam dilingkungan sekitarnya.

Dengan mempelajari kenampakan alam sesuai dengan daerah tempat tinggalnya, diharapkan dimasa mendatang siswa memiliki pengetahuan tentang daerahnya dan lebih lanjut mampu mengelola serta mengadakan pembangunan untuk kesejahteraan masyarakat. Sesuai dengan tujuan mata pelajaran IPS yaitu untuk mengembangkan potensi peserta didik agar peka terhadap masalah sosial yang terjadi dimasyarakat, memilki sikap mental positif terhadap perbaikan segala ketimpangan yang terjadi, dan terampil mengatasi setiap masalah yang terjadi sehari-hari baik yang menimpa dirinya sendiri maupun yang menimpa masyarakat.

Hal ini juga terjadi pada siswa SD kelas V Kabupaten Pacitan, dimana siswa mempelajari IPS materi kenampakan alam pada buku yang hanya menampilkan kenampakan alam daerah atau kota lain, sedangkan kenampakan alam Kabupaten Pacitan belum ditampilkan untuk menjadi bahan ajar bagi siswa SD kelas V Kabupaten Pacitan. Kenampakan alam apa saja yang terdapat di Kabupaten Pacitan dan memiliki potensi untuk dijadikan bahan ajar IPS kelas V SD. Untuk itu maka penelitian ini perlu dilaksanakan.

Berdasarkan latar belakang masalah di atas, maka rumusan masalahnya yaitu apa saja kenampakan alam yang terdapat di Kabupaten Pacitan 
Avaliable online at http://e-journal.unipma.ac.id/index.php/gulawentah

dan memiliki potensi untuk dijadikan bahan ajar IPS kelas V SD?

Tujuan penelitian ini adalah untuk mendapatkan gambaran atau deskripsi tentang kenampakan alam Kabupaten Pacitan sebagai bahan ajar IPS kelas V SD.

Kenampakan alam adalah segala sesuatu yang ada di alam yang terbentuk karena peristiwa alam (Sutoyo dan Agung, 2009: 21). Sedangkan menurut Pujiati dan Yuliati (2008: 22) kenampakan alam merupakan bentuk muka bumi. Kenampakan alam disebut juga dengan istilah bentang alam. Dari berbagai pendapat di atas, maka dapat disimpulkan bahwa kenampakan alam adalah segala sesuatu yang ada di alam. Kenampakan yang terjadi karena peristiwa alam disebut kenampakan alam.

Bahan ajar adalah segala bentuk bahan yang digunakan untuk membantu guru atau instruktor dalam melaksanakan kegiatan belajar mengajar agar tujuan pembelajaran dapat tercapai. Bahan yang dimaksud bisa berupa bahan tertulis maupun bahan tidak tertulis (Majid, 2011:173). Hal serupa juga disampaikan oleh (Wiyani, 2013: 132) bahan cetak atau printed material merupakan berbagai informasi sebagai materi pembelajaran yang disimpan dalam bentuk tercetak. Sementara itu, bahan belajar noncetak adalah informasi sebagai materi pembelajaran yang tersimpan dalam berbagai bentuk alat komunikasi elektronik yang biasanya digunakan sebagai media pembelajaran. Dari berbagai pendapat di atas, maka dapat disimpulkan bahwa bahan ajar merupakan seperangkat materi atau substansi pembelajaran yang disusun secara sistematis baik berupa bahan ajar cetak maupun bahan ajar noncetak untuk membantu guru melaksanakan kegiatan belajar mengajar. Bahan ajar juga merupakan arahan bagi siswa untuk mencapai kompetensi yang diharapkan dalam kegiatan pembelajaran.

Menurut Majid (2011: 174) ada 4 jenis bahan ajar, yaitu: (a) Bahan cetak (printed) antara lain handout, buku, modul, lembar kerja siswa, brosur, leaflet, wallchart, foto/ gambar, model/maket. (b) Bahan ajar dengar (audio) seperti kaset, radio, piringan hitam, dan compact disk audio. (c) Bahan ajar pandang dengar (audio visual) seperti video compact disk, film. (d) Bahan ajar interaktif (interactive teaching material) seperti compact disk interaktif.

Fungsi bahan ajar disampaikan oleh Hamdani (2011: 121), sebagai berikut: (1) Pedoman bagi guru yang akan mengarahkan semua aktivitasnya dalam proses pembelajaran, sekaligus merupakan substansi kompetensi yang seharusnya diajarkan kepada siswa. (2) Pedoman bagi siswa yang akan mengarahkan semua aktivitasnya dalam proses pembelajaran, sekaligus merupakan substansi kompetensi yang seharusnya dipelajari atau dikuasai. (3) Alat evaluasi pencapaian atau penguasaan hasil pembelajaran.

Berdasarkan pendapat-pendapat yang telah diuraikan diatas dapat disimpulkan bahwa bahan ajar merupakan bagian penting dalam pelaksanaan pendidikan di sekolah. Melalui bahan ajar guru akan lebih mudah dalam melaksanakan 
Avaliable online at http://e-journal.unipma.ac.id/index.php/gulawentah

pembelajaran dan siswa akan lebih terbantu dan mudah dalam belajar. Penggunaan berbagai jenis bahan ajar memiliki keuntungan masing-masing dan bertujuan untuk membuat materi pembelajaran tersampaikan dengan baik.

Bertolak dari pengertian di atas, maka bahan ajar dalam penelitian ini yaitu kenampakan alam Kabupaten Pacitan yang diwujudkan dalam bentuk buku.

Menurut Anshori (2014: 63) IPS yang diajarkan di sekolah dasar menjadi dasar pengantar untuk mempelajari IPS di jenjang sekolah yang lebih tinggi, hal ini dikarenakan materi yang diajarkan memiliki keterkaitan dari jenjang yang rendah ke jenjang yang lebih tinggi, materi IPS disampaikan dari yang sederhana menuju ke materi yang lebih kompleks. Pada prinsipnya pendidikan IPS di sekolah dasar tidak mengajarkan ilmu-ilmu sosial sebagai disiplin ilmu, melainkan konsep esensi ilmu-ilmu sosial untuk membentuk siswa menjadi warga negara yang baik (good citizen). Sedangkan tujuan dari IPS disampaikan oleh Afandi (2011: 88), yaitu membina anak didik menjadi warga negara yang baik, yang memiliki pengetahuan, keterampilan dan kepedulian sosial yang berguna bagi dirinya sendiri serta bagi masyarakat dan bagi negara.

\section{Metode Penelitian}

Penelitian ini menggunakan jenis penelitian deskriptif dengan pendekatan kualitatif. Sumber data pada penelitian ini adalah sumber data primer dan sumber data sekunder, Penelitian ini menggunakan sumber data berupa katakata yang didapat dari informan yang diwawancarai, tempat yang berupa lokasi kenampakan alam, dan beberapa dokumen. Teknik pengumpulan data dalam penelitian ini menggunakan wawancara, observasi, dan dokumentasi. Pada penelitian ini prosedur penelitiannya ada 3 tahap, yaitu (1) tahap persiapan (2) tahap pelaksanaan (3) tahap penyelesaian. Untuk teknik keabsahan data pada penelitian ini menggunakan triangulasi sumber. Analisis data dalam penelitian ini menggunakan teknis analisis data model Miles dan Huberman yaitu analisis model interaktif.

\section{Hasil dan Pembahasan}

Kabupaten Pacitan merupakan daerah dengan kondisi alamnya berupa dataran rendah dan perbukitan. Kenampakan alam yang ada di Kabupaten Pacitan juga beragam, diantara kenampakan alam tersebut adalah kenampakan alam pantai, gua, sungai, gunung, telaga, dan sumber air panas. Jenis kenampakan alam dengan jumlah terbanyak yang ada di Kabupaten Pacitan adalah kenampakan alam pantai, terdapat 60 pantai di Kabupaten Pacitan. Selain pantai, gua juga merupakan kenampakan alam Kabupaten Pacitan yang jumlahnya tidak sedikit, bahkan Pacitan memiliki julukan kota 1001 gua. Diantara gua yang ada di Kabupaten Pacitan ada yang sudah dikelola namun banyak juga gua yang belum dikelola, baik oleh pemerintah daerah maupun oleh masyarakat sekitar. Untuk kenampakan alam sungai, di Kabupaten Pacitan juga terdapat banyak sungai, namun dari beberapa sungai tersebut ada yang digunakan untuk tempat wisata, 
Avaliable online at http://e-journal.unipma.ac.id/index.php/gulawentah

tempat aktivitas kenelayanan, dan ada sungai yang digunakan sebagai tempat pertambangan, sungai terpanjang di Kabupaten Pacitan adalah Sungai Grindulu.

Kabupaten Pacitan juga merupakan daerah pegunungan, salah satu gunung yang ada di Kabupaten Pacitan adalah Gunung Limo. Gunung Limo ini selain sebagai lokasi pendakian juga sering digunakan untuk lokasi wisata spiritual, Gunung Limo masih sering digunakan sebagai tempat bertapa bahkan ada upacara untuk menghormati orang-orang yang bertapa tersebut, yaitu upacara Tetaken yang diadakan pada tanggal 5 bulan Suro. Untuk kenampakan alam berupa telaga di Kabupaten Pacitan belum dapat diperkirakan jumlahnya, salah satu telaga yang ada di Kabupaten Pacitan adalah Telaga Sono. Di Kabupaten Pacitan juga terdapat sumber air panas yang kemudian di kelola oleh masyarakat menjadi pemandian air hangat Tirto Husodo. sumber air panas ini merupakan kenampakan alam yang cukup unik, karena ternyata air panasnya bukan berasal dari gunung berapi sehingga sangat sedikit sekali mengandung belerang.

Berdasarkan paparan di atas dapat diketahui bahwa kenampakan alam Kabupaten Pacitan memiliki potensi yang besar, baik sebagai sumber daya alam maupun sebagai lokasi wisata. Masyarakat khususnya peserta didik tentu saja perlu memahami dan mengetahui tentang potensi-potensi ini, agar kedepannya dapat mengelola dan lebih lanjut dapat memajukan daerahnya. Kenampakan alam Kabupaten Pacitan memiliki potensi untuk dijadikan bahan ajar IPS. Kenampakan alam Kabupaten Pacitan yang layak dijadikan sebagai bahan ajar IPS kelas V SD adalah : (1) Kenampakan alam pantai meliputi Pantai Pidakan, Pantai Kasap, dan Pantai Klayar. (2) Kenampakan alam gua meliputi Gua Gong dan Gua Tabuhan. (3) Kenampakan alam Sungai meliputi Sungai Maron, Sungai Cokel, dan Sungai Grindulu. (4) Kenampakan alam Gunung Limo. (5) Kenampakan alam Telaga Sono. (6) Kenampakan alam sumber air panas.

Kenampakan alam Kabupaten Pacitan dengan jumlah paling banyak adalah kenampakan alam pantai, diantara pantai yang ada di Kabupaten Pacitan adalah pantai Kasap, Pantai Klayar, dan Pantai Pidakan. Pantai Kasap merupakan pantai di Desa Watukarung Kecamatan Pringkuku Kabupaten Pacitan yang memiliki potensi besar dan diminati oleh wisatawan, namun pengelolaan yang ada di Pantai Kasap ini belum maksimal. Keindahan Pantai Kasap adalah adanya bukit-bukit kecil di pantainya, pemandangan tersebut hampir sama dengan pemandangan di Raja Ampat Papua. Sedangkan Pantai Pidakan merupakan pantai unik yang berlokasi di Desa Jetak Kecamatan Tulakan Kabupaten Pacitan. Keunikan pantai ini terletak pada komposisi material pada bibir pantai, sebagian besar materialnya adalah batuan alam, komposisi batuan alam ini mencapai $70 \%$. Keunikan pantai di Kabupaten Pacitan juga dimilik oleh Pantai Klayar, keunikan tersebut berupa adanya seruling samudera yang dapat menghasilkan suara seperti siulan dan 
dapat terdengar hingga jarak $2 \mathrm{~km}$. Selain itu, Pantai Klayar juga memiliki keindahan alam berupa pasir putih dan tebing-tebing karang.

Kenampakan alam Gua di Kabupaten Pacitan yang paling diminati oleh wisatawan karena keindahannya adalah Gua Gong dan Gua Tabuhan. Gua Gong yang terletak di Desa Bomo Kecamatan Punung Kabupaten Pacitan ini memiliki potensi yang besar untuk dikembangkan sebagai daerah wisata, Gua Gong memiliki keindahan berupa stalagtit dan stalagmit di sepanjang lorong Gua, bahkan ada stalagtit dan stalagmit yang menyatu hingga membentuk seperti tiang. Potensi yang besar juga dimiliki Gua Tabuhan. Gua Tabuhan memiliki keindahan berupa stalagtit dan stalagmit yang panjangnya menyerupai pilar-pilar raksasa, panjangnya dapat mencapai 7 meter dengan diameter 1 meter. Selain itu, gua ini juga unik karena stalagtit dan stalagmitnya dapat menghasilkan bunyi gamelan.

Sungai di Kabupaten Pacitan juga memiliki berbagai potensi, diantara sungai-sungai Kabupaten Pacitan adalah Sungai Maron, Sungai Cokel, dan Sungai Grindulu. Sungai Maron adalah sungai di Kabupaten Pacitan yang kini tengah diminati oleh wisatawan. Keindahan sungai ini sering dijuluki dengan "Amazonnya Pacitan". Selain potensi wisata, Sungai Maron juga dijadikan sebagai tempat tambak ikan oleh masyarakat sekitar, namun tambak ikan yang dirintis oleh masyarakat masih dalam skala kecil. Sedangkan Sungai Cokel merupakan sungai yang memiliki air jernih yang tampak kehijauan. Sungai
Cokel ini sangat besar manfaatnya untuk para nelayan. Sungai Cokel dijadikan sebagai tempat untuk parkir perahu dan alat tangkap nelayan. Potensi alam yang besar juga dimilik oleh Sungai Grindulu merupakan sungai terpanjang di Kabupaten Pacitan, panjang Sungai Grindulu mencapai 70 km, Sungai Grindulu menyimpan berbagai potensi alam yang dimanfaatkan masyarakat sekitar untuk kebutuhan sehari-hari. Masyarakat menambang pasir dan batu dari Sungai Grindulu, petani juga membuat saluran irigasi yang bersumber dari Sungai Grindulu.

Salah satu kenampakan alam gunung yang ada di Kabupaten Pacitan adalah Gunung Limo. Gunung Limo merupakan gunung di Kabupaten Pacitan yang digunakan sebagai lokasi wisata pendakian dan juga wisata spiritual. Gunung Limo memiliki ketinggian 668 mdpl, dari atas puncak Gunung Limo dapat terlihat pemandangan hijaunya Kota Pacitan. Setiap tanggal 15 Suro/ Muharram di Gunung Limo ini dilaksanakan upacara Tetaken. Upacara Tetaken adalah upacara yang juga termasuk aset budaya Kota Pacitan, dalam upacara Tetaken ini para pertapa dan juru kunci turun gunung dan dilakukan acara sedekah bumi oleh masyarakat sekitar.

Kenampakan alam telaga yang terdapat di Kabupaten Pacitan salah satunya adalah Telaga Sono. Telaga ini sering digunakan sebagai tempat memancing oleh masyarakat sekitar, selain itu telaga ini juga dimanfaatkan masyarakat sekitar untuk irigasi pertanian. Dengan adanya bukit-bukit serta gunung Tipis yang mengelilingi 
Avaliable online at http://e-journal.unipma.ac.id/index.php/gulawentah

telaga, didukung dengan suasana pedesaan maka telaga ini terlihat asri. Telaga ini juga mulai dirintis sebagai tempat pariwisata.

Kabupaten Pacitan juga memiliki potensi alam berupa sumber air panas. Sumber air panas yang ada di Desa Karangrejo Kecamatan Arjosari Kabupaten Pacitan kini dikelola mejadi pemandian air hangat "Tirto Husodo". Sumber air panas ini bukan dari gunung berapi, berdasarkan penelitian geologi sumber air panas itu ditemukan dari gesekan lempeng bumi yang dialiri air sehingga air tersebut menjadi panas dan mengandung belerang yang kadarnya sangat sedikit.

\section{Kesimpulan}

Kenampakan alam Kabupaten Pacitan memiliki potensi yang besar, baik sebagai sumber daya alam maupun sebagai lokasi wisata. Masyarakat khususnya peserta didik perlu memahami dan mengetahui tentang potensi dari kenampakan alam Kabupaten Pacitan, agar kedepannya dapat mengelola dan lebih lanjut dapat memajukan daerahnya. Kenampakan alam Kabupaten Pacitan yang memiliki potensi, keunikan, dan diminati wisatawan sehingga membutuhkan pengelolaan yang lebih baik layak dijadikan sebagai bahan ajar IPS kelas V SD. Kenampakan alam tersebut adalah adalah sebagai berikut: (1) Kenampakan alam pantai meliputi Pantai Pidakan, Pantai Kasap, dan Pantai Klayar. (2) Kenampakan alam gua meliputi Gua Gong dan Gua Tabuhan.

Kenampakan alam Sungai meliputi Sungai Maron, Sungai Cokel, dan Sungai Grindulu. (4) Kenampakan alam
Gunung Limo. (5) Kenampakan alam Telaga Sono. (6) Kenampakan alam sumber air panas.

Bahan ajar yang digunakan dalam pembelajaran IPS adalah untuk membantu dalam pencapaian tujuan pembelajaran IPS. Untuk mencapai tujuan pembelajaran IPS kelas V SD materi kenampakan alam maka perlu digunakan bahan ajar yang sesuai dengan lingkungan atau daerah tempat tinggal siswa. Dengan dijadikannya kenampakan alam Kabupaten Pacitan sebagai bahan ajar maka peserta didik khususnya peserta didik Kabupaten Pacitan dapat mempelajari tentang kenampakan alam yang ada di daerahnya.

Kenampakan Alam Kabupaten Pacitan memiliki potensi yang besar, baik sebagai objek wisata maupun sebagai sumber daya alam. Berdasarkan hal tersebut, masyarakat Kabupaten Pacitan disarankan agar selalu melestarikan potensi alam Kabupaten Pacitan, agar alam Kabupaten Pacitan selalu lestari dan membawa manfaat yang diharapkan oleh masyarakat. Selain masyarakat, pemerintah Kabupaten Pacitan juga diharapkan mampu meningkatkan pengelolaan terhadap kenampakan alam Kabupaten Pacitan. Sehingga kenampakan alam Kabupaten Pacitan dapat membawa manfaat bagi masyarakat dan pada sektor wisata kenampakan alam Kabupaten Pacitan semakin diminati oleh wisatawan asing maupun lokal.

Peneliti juga berharap kepada seluruh guru khususnya guru IPS SD supaya lebih kreatif dalam melaksanakan kegiatan belajar 
Avaliable online at http://e-journal.unipma.ac.id/index.php/gulawentah

mengajar, hal ini bertujuan agar siswa tidak bosan dan semakin tertarik untuk belajar. Guru juga harus pandai dan cermat terhadap potensi yang ada di lingkungan sekitarnya. Karena dalam pembelajaran IPS materi kenampakan alam, siswa seharusnya mempelajari potensi lingkungan sekitarnya kemudian belajar tentang potensi daerah lain atau nasional.

Diharapkan ada penelitian lain yang berhubungan dengan kenampakan alam atau potensi alam di daerahnya masing-masing, sehingga dengan banyaknya penelitian tentang kenampakan alam dari berbagai daerah maka akan menambah referensi bacaan tentang kenampakan alam.

\section{Daftar Pustaka}

Afandi, R. (2011). Integrasi Pendidikan Karakter dalam Pembelajaran IPS di Sekolah Dasar. Pedagogia. 1(1): 88 .

Anshori, S. (2014). Kontribusi Ilmu Pengetahuan Sosial dalam Pendidikan Karakter. Jurnal Edueksos. 3(2):63.

Hamdani.(2011). Strategi Belajar Mengajar.Bandung: Pustaka Setia.

Majid, A. (2011). Perencanaan Pembelajaran Mengembangkan Standar Kompetensi Guru. Bandung: Remaja Rosdakarya.

Pujiati, R.H. \& Yuliati, U. (2008). Cerdas Pengetahuan Sosial. Jakarta: Pusat Perbukuan, Departemen Pendidikan Nasional

Sutoyo, L.A. (2009). Ilmu Pengetahuan Sosial 4. Jakarta: Pusat Perbukuan, Departemen Pendidikan Nasional.

Wiyani, N.A. (2013). Desain Pembelajaran Pendidikan Tata Rancang Pembelajaran Menuju Pencapaian Kompetensi. Yogyakarta: Ar-Ruzz Media. 